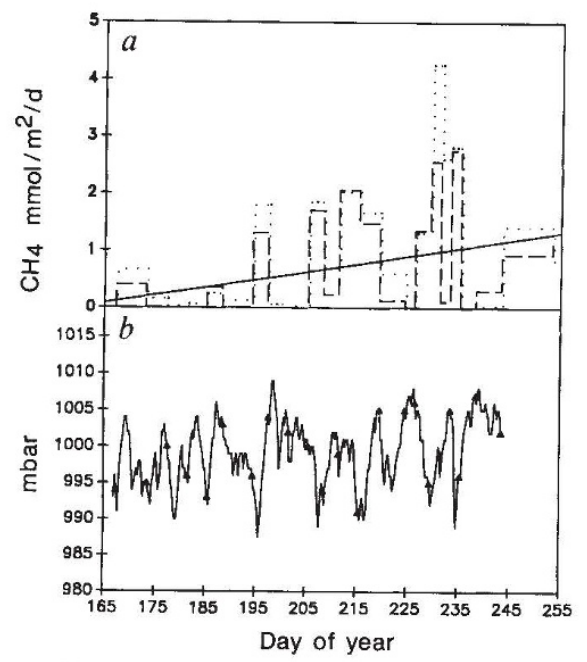

a. Methane ebullition rates at two sites (10-m depth) during 1987 in Mirror Lake, New Hampshire. Dashed vertical bars, rates and the sampling intervals versus day of the year. The line is the best-fit regression of the rate versus time. $b$, Associated air pressure (J. Zabranski, unpublished data). Triangles, beginning and end of the sampling periods.

more than half the methane flux occurred during two sampling intervals in only 10 days. These two periods of rapid methane ebullition corresponded to the two lowest air-pressure events of the summer: the first (985 mbar) occurred with a heavy rainfall on 5 August, the second (982 mbar) was associated with the passage of (former) hurricane Hugo on 23 September.

The change in air pressure we measured was only $1-3 \%$, yet we believe this change directly affected the volume of the gas bubbles in the sediments. Observations of pores on the lake bottom suggest ${ }^{6}$ that bubbles within the sediments occupy vertical 'bubble tubes'. When pressure falls, expansion of the bubbles is limited to the vertical, resulting in bubble release. Others have noted an apparent hysteresis effect on ebullition ${ }^{7}$, which implies that flux rates may not be a simple linear function of pressure changes.

Highly sporadic, yet synchronous ebullition has also been reported in other sediments ${ }^{6-11}$. There are also reports of gas

1. Rasmussen, R.A. \& Khalil, M.A.K. J. geophys. Res. 86 9826-9832 (1981)

2. Pearman, G.I., Etheridge, D., de Silva, F. \& Fraser, P.J. Nature 320, 248-250 (1986).

3. Likens, G.E. An Ecosystem Approach to Aquatic Ecology: Mirror Lake and its Environment (Springer-Verlag, New York, 1985).

4. Mattson, M.D. thesis, Cornell Univ. (1989).

5. Chau, Y.K., Snodgrass, W.J. \& Wong, P.T.S. Water Res. 11, 807-809 (1977)

6. Martens, C.S. \& Klump, J.V. Geochim. cosmochim. Acta. 44, 471-490 (1980)

7. Chanton, J.P., Martens, C.S. \& Kelley, C.A. Limnol Oceanogr. 34, 807-819 (1989).

8. Jones, J.G. \& Simon, B.M. J. gen. Microbiol. 123, $297-$ 312 (1981)

9. Baker-Biocker, A., Donahue, T.M. \& Mancy, K.H. Tellus 29, 245-250 (1977).

10. Rossolimo, L. Verh. Int. Verein. Limnol. 7, 539-56. (1935).

11. Molongoski, J.J. \& Klug, M.J. Freshwater Biol. 10, 507 $518(1980)$

12. Clements, W.E. \& Wilkening, M.H. J. geophys. Res. 79 5025-5029 (1974) release from soils being triggered by lowpressure events ${ }^{12}$. As most studies do not sample ebullition continuously, they may not sample the main ebullition events, particularly when sampling tends to occur during fair weather (at high air pressure). Attempts to reduce the sampling variability by extending the collection interval to longer periods (say weeks) may result in serious underestimates due to diffusion and/or oxidation losses in the traps.

MARK D. MATTSON* GENE E. LIKENS

Institute of Ecosystem Studies,

The New York Botanical Garden,

Box AB, Millbrook,

New York 12545, USA

* Present address: Water Resources Research Center, Blaisdell House, University of Massachusetts. Amherst, Massachusetts 01003 , USA.

\section{Flight of the bumblebee}

SiR-The letter by C. P. Ellington et al. (Nature 347,472;1990) on the flight of bumblebees has stimulated me to resurrect my own answer to the problem of bumblebee flight, put forward in a paper that was rejected by the Journal of Experimental Biology, I think in 1950.

The theoretical difficulty in understanding how a bee can fly, and in particular how it can hover, is as follows. A hovering insect supports its weight by projecting downwards a jet of air. Then $W=m v$, where $W$ is the weight of the insect, $v$ is the velocity of the jet and $m$ is the mass of air traversing the jet in unit time. Clearly, $m$ $=r a v$, where $r$ is the density of air and $a$ is the cross-sectional area of the jet. Knowing the weight and wing span, one can estimate $a$ from the standard theory of aircraft propellors, and hence can estimate $v$. The kinetic energy added to the air in unit time is $m v^{2} / 2$.

The snag is then as follows. Comparing this estimate of the necessary work being done with estimates of the rate at which sugar is used by a tethered flying insect suggested an overall efficiency that approached 100 per cent, which seemed implausible.

My fellow undergraduate at University College London, M. J. Davis, and I therefore decided to measure the direction and velocity of the airflow round a tethered flying insect. We used hoverflies because we found bees reluctant to fly when tethered. We surrounded the insect with particles of metaldehyde and photographed it with a flashbulb, timing the flash with a strip of bromide paper on the rim of a gramophone. The resulting photographs were fairly awful by modern standards, but were good enough to show that the velocity of the air in the jet was about one-third of the theoretical value, and the area of the jet correspondingly greater. Because of viscosity, the air that actually passes through the disk swept out by the wings drags along with it a substantially larger volume of air. The answer to the conundrum of bumblebee flight is that, at low Reynold's number, the bee handles a larger volume of air than its small wing span might suggest.

School of Biological Sciences,

J. MAYNARD SMITH

University of Sussex,

Brighton BN1 9QG, UK

\section{Meaning of life}

SIR-In his paper" entitled "How Long Do Neutrons Live?", Freedman does us all a service by collating and assessing current estimates of neutron lifetime. His conclusion, that the weighted mean of the various estimates of lifetime is $887.6 \pm 2.7$ seconds, is given to three significant figures, but unfortunately some readers may have a significant doubt as to what quantity is actually being enumerated.

Dictionaries define lifetime as "the time during which an individual lives". The decay of neutrons in free space being a random process, it follows that Freedman's result cannot apply to the lifetime of any individual neutron. It must, therefore, be either the mean-life or the half-life. But which?

A survey of colleagues in this department showed that a number of them were unsure, their conclusion probably being based on past experience. Those of us reared on earlier editions of the Handbook of Chemistry and Physics ${ }^{2}$ know of a column labelled 'lifetime' in the table of isotopes. The explanation to the table defined 'lifetime' as being 'half-life'. Some time between 1975 and 1987 , the editors changed the column label to the totally unambiguous 'half-life'. On reading Freedman's paper my first reaction, and that of some others also, was to believe that the latest estimates of neutron halflife were longer than those previously proposed. In fact, Freedman reports an improved value for the mean lifetime. The usage of lifetime to define this quantity may be clearly understood in the particlephysics community, but is not necessarily clear to the wider audience to whom a result of this type could well be of considerable interest.

The difference between mean-life and half-life is a factor of 0.693 . It is important that authors make it clear which of the two they are reporting.

\section{Department of Physics, University of Tasmania, GPO Box 252C,}

Hobart, Tasmania 7001 ,

\section{Australia}

1. Freedman, S. Comments Nucl. Part. Phys. 19, 209 (1990).

2. Handbook of Chemistry and Physics 55th edn (CRC, 1974-75). 